\title{
Book review on Who is Who in Thermal Analysis and Calorimetry
}

This is the second time, when Who is Who in Thermal Analysis and Calorimetry has been published. The major goal of this book is to collect those scientists who are working in the field of thermal analysis. The first version was released in 2004. Ten years have passed since then. One of the original editors (Prof. George Liptay) felt that an updated version should be published, and my opinion is that this was a great idea. I have to note that the former editor was right, because 10 years is a long time and lot of changes appear in the book, even if we compare the datasheets of those researchers, who appear in both books. Let me put a personal remark here that this area is not very large and most of the scientists working in this field know each other. That is why this book has special charm. In addition, I have to highlight that numerous young scientists appear in the second edition indicating that this field develops dynamically, because thermal analysis is one of the basic methods of material characterization and material science. The second updated version (Fig. 1) has similar style as the original one. The editors of this book (prof. Imre Miklós Szilágyi and prof. George Liptay) did a great job to collect the 341 scientists in this nice publication. Every researcher has one page, which is edited carefully, so it is clear that the editors put a lot of effort to bring the information in the book to a homogeneous style; thus, the appearance of the book is very nice. Good quality photos are presented about all researchers, so this book is also very useful for those who are new in this area and start their scientific career now. Moreover, I have to point out that the collection of this database is very useful for the senior researchers too, because they can check the research areas as well as the changes in the research fields of scientists. Consequently, this book can be opened any time if a scientist has a scientific question and I am sure that experts, who can answer that question on the certain fields of thermal analysis and calorimetry, can be found easily.

Finally, thanks for the editors for their great work to edit this book. I was very happy when I took this book first time in my hands and opened it. I hope that the same editors will edit the third edition as well and I congratulate them for their great job again.

Alfréd Kállay-Menyhárd Editor-in-Chief

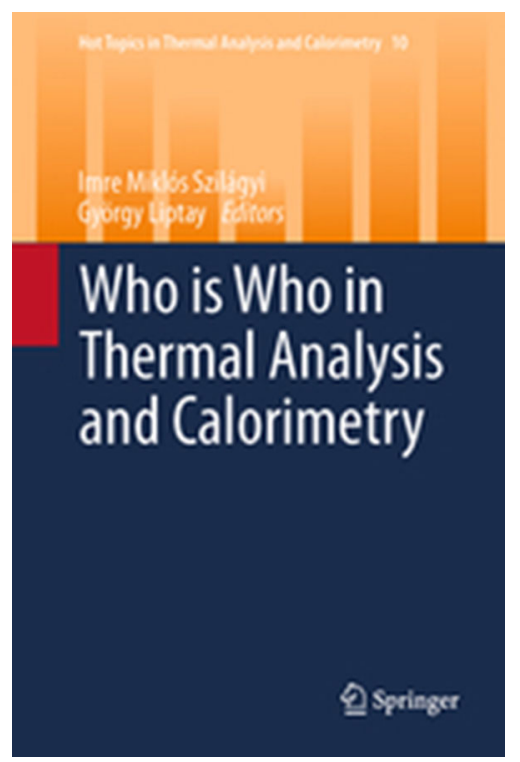

Fig. 1 The second edition of Who is Who 